\title{
Experiences of Recurrent Pregnancy Loss Through the Perspective of United Arab Emirates Women: A Qualitative Study
}

\author{
Fatima Muhammad Ibrahim $^{1}$, Shamsa Abdulmanan Abdul Rahman Al Awar ${ }^{2}$, Nahid Dehghan Nayeri $^{3}$, \\ Moamar Al-Jefout ${ }^{4,5}$, Fahimeh Ranjbar ${ }^{6}$, Zahra Behboodi Moghadam ${ }^{7 *}$ (D)
}

\begin{abstract}
Objectives: The aim of this study was to evaluate the perception and experience of recurrent pregnancy loss through the perspective of women in the United Arab Emirates (UAE).

Materials and Methods: This qualitative study was conducted in 2017 and 12 women with recurrent miscarriage were interviewed, using purposive sampling method, in the Medical and Health Clinic of the Department of Obstetrics and Gynecology under the supervision of the UAE Medical University. Transcribed interviews were analyzed using conventional content analysis.

Results: Data analysis led to the extraction of three main themes, including endless pregnancy, thirst for support and affirmation, and religious beliefs.

Conclusions: Overall, the experience of recurrent miscarriage means endless pregnancy from Arab women's perspective, which awakened a thirst for support and affirmation. In this regard, the utilization of religious beliefs greatly reduced their pain. Therefore, knowing the dangers and consequences of recurrent miscarriages in Arab women, adopting preventative measures, and improving the quality of care in these vulnerable women require special attention.

Keywords: Recurrent miscarriage, Perception, Experience, United Arab Emirates, Qualitative study
\end{abstract}

\section{Introduction}

The birth of a baby is one of the happiest events that a couple can experience together. However, this experience can be fraught with frustration and challenges such as pregnancy complications or fetal loss, abortion, the birth of a dead baby, and fetal abnormalities (1). Nearly a quarter of pregnancies eventually lead to abortions (2). Among different kinds of abortion, recurrent miscarriage or habitual abortion is described as a relatively complicated issue. In addition, recurrent pregnancy loss refers to three or more consecutive miscarriages (3) and the risk of abortion increases after each abortion in such a way that the probability of recurrent miscarriage is $24 \%$, $30 \%$, and $40 \%-50 \%$ after 2,3 , and 4 abortions, respectively (4). Generally, this occurs in about $1 \%$ of couples who intend to have a child (3). According to a previous report, recurrent miscarriages account for $10 \%$ of the total pregnancies at Al-Noor Private Hospital in Abu Dhabi (5). Although the fertility rate in the United Arab Emirates (UAE) shows a decrease from 3.29 to 2.36 during 2002-2014, fertility and pregnancy are nonetheless considered as important social values (6). In the UAE, families with more children enjoy more privileges and national policies pay special attention to the issue of fertility, therefore, people recognize the importance of childbearing and consider it as a norm (7).

Abortion is overshadowed by many factors such as sharia, tradition, custom, law, and morality and affected by different psychological, social, and biological factors. Thus, abortion is not only a health problem which incurs high costs on society by imposing many complications but is also considered a social problem in all communities since it, ultimately, endangers the health status of families and societies (8). The results of various studies emphasized various abortion-related problems that can affect women's personal lives and concluded that there are changes in women's feelings six weeks after abortion and the termination of pregnancy, which affect women mentally $(2,9)$. For example, abortion leads to the feelings of emptiness and a sense of guilt and negatively influences women's minds (10). Further, women with spontaneous abortion suffer from the twofold risk of major depression, which begins in the first week after abortion in most women and is more severe in the cases of recurrent miscarriages (4). Since recurrent miscarriage is usually 
referred to as a female problem, women suffering from this problem encounter more familial and social problems than men. Thus, recurrent miscarriage can cause mental harm, family threats, remarriage, separation, and divorce (5). Although recurrent abortion affects about $1 \%$ of the couples, it is one of the most devastating and most catastrophic complications of pregnancy (11). Despite the above-mentioned negative consequences, the experience of women with recurrent pregnancy loss has attracted less attention and there is no study regarding the experience of women with recurrent miscarriage in the UAE. Therefore, more research is needed to clarify the darker aspects of the lives of women who experience recurrent miscarriage. Accordingly, the present study aimed to explain the perception and experiences of Arab women concerning recurrent miscarriages by taking into account different social and cultural norms and values in the UAE.

\section{Materials and Methods}

The current qualitative study was conducted in 2017 seeking to explain the perception and experience of Arab women about recurrent miscarriage. To this end, 12 women with an experience of three or more consecutive miscarriages were selected using a purposive sampling technique at the Medical and Health Clinic of the Department of Obstetrics and Gynecology of the UAE University in Al-Ain. Furthermore, the inclusion criteria included Emirati and Arabic-speaking women with a history of recurrent pregnancy loss, which refers to three or more consecutive miscarriages (12). Women, who were willing to participate in the research, were requested to study, complete, and sign the informed consent form. The data were mainly collected through in-depth semistructured interviews conducted during NovemberDecember 2017. Moreover, interviews were recorded after obtaining the participants' permission, followed by saturating the obtained data. Additionally, the interviews were initiated with open questions and continued with exploratory questions. After being completed, each interview was written word-by-word and coded and the next interview was performed after analyzing the previous one. Each interview lasted between 30 and 75 minutes with an average duration of 52 minutes. If necessary, the interviews were conducted based on the participants' opinions, for example, in a coffee shop, their homes, or their mothers' homes where they felt more comfortable. First, each participant answered questions about her age, spouse's age, the duration of the marriage, the number of living or dead children and abortions, the time of the last abortion, the level of education, and job. Then, one open question was asked like "What is a recurrent miscarriage in your opinion?" or "What does it mean to have recurrent miscarriages as an Emirati woman?", followed by exploratory questions such as "Can you explain more" or "What do you mean when you say...?" Data analysis and data collection were performed simultaneously with constant comparison. The texts of the interviews were frequently read to obtain a general perception of the data. Then, they were further analyzed using the conventional content analysis approach proposed by Graneheim and Lundman (13) and the extracted codes were managed using MAXQDA10 software. Similarity, the criteria by Lincoln and Guba, including credibility, dependability, confirmability, and transferability were used to ensure data accuracy and authenticity (14).

Confirmability was utilized for member checking and peer review methods. In other words, some of the participants were asked to study the interview transcriptions and extracted codes in order to find whether they were based on their experiences. In the peer review method, interviews were coded and all the stages of the analysis were investigated by consulting and cooperating with all research members. Likewise, data transferability was achieved by providing participants' characteristics, data collection method, and analysis, along with presenting several examples of their interviews to allow others to conduct the research.

\section{Results}

Participants included 12 women with recurrent miscarriages within the age range of 25-42 years old. Three of the participants had children and the number of (consecutive) abortions was 3 to 8 among the women. The last abortion occurred during the last 1 to 12 months (Table 1). Totally, 3 themes and 7 sub-themes were extracted after analyzing 16 interviews conducted to reveal the meaning of the recurrent miscarriages though the lens of UAE women, the details of which are provided in Table 2.

\section{Endless Pregnancy}

The theme of endless pregnancy encompassed two subthemes, namely, brittle pregnancy, along with painful and endless suffering for motherhood.

\section{Brittle Pregnancy}

It shows the instability and fragility of pregnancy. According to participant No. 5 (39 years old): "On the one hand, you are becoming a mother and having children, on the other hand, you can no longer become pregnant and have a baby and you do not get any result. My pregnancy is fragile and like a glass". In addition, participant No. 3 (42 years old) indicated that: "I was pregnant for the eighth time, but it (embryo) was aborted again. I feel like my pregnancies are fragile".

\section{Painful and Endless Suffering for Motherhood}

Painful and endless suffering for motherhood was often reported by most participants, and they felt the regret of motherhood and becoming a mother for the second time. Participant No. 1 (36 years old), who had a living child, declared that: "I took a lot of medicine for this pregnancy, and I was very tolerant of the effect of medicines, but it ended 
Table 1. Demographic Characteristics of Participants

\begin{tabular}{|c|c|c|c|c|c|c|c|}
\hline Number & Age & Educational Level & Employment Status & $\begin{array}{c}\text { Duration of } \\
\text { Marriage }\end{array}$ & $\begin{array}{c}\text { Number of } \\
\text { Children }\end{array}$ & Abortion & $\begin{array}{c}\text { Time of Last } \\
\text { Abortion (month) }\end{array}$ \\
\hline 1 & 36 & Master & Employee & 8 & 2 & 6 & 6 \\
\hline 2 & 25 & Diploma & Housewife & 5 & 0 & 3 & 3 \\
\hline 3 & 42 & Elementary & Housewife & 30 & 0 & 8 & 4 \\
\hline 4 & 36 & Diploma & Housewife & 17 & 3 & 6 & 2 \\
\hline 5 & 39 & Bachelor & Employee & 20 & 3 & 7 & 3 \\
\hline 6 & 38 & Bachelor & Self-Employed & 15 & 4 & 3 & 2 \\
\hline 7 & 29 & Bachelor & Housewife & 10 & 1 & 3 & 4 \\
\hline 8 & 25 & Bachelor & Self-Employed & 3 & 0 & 5 & 1 \\
\hline 9 & 38 & Elementary & Housewife & 23 & 4 & 5 & 5 \\
\hline 10 & 39 & Elementary & Housewife & 20 & 10 & 6 & 2 \\
\hline 11 & 35 & Elementary & Housewife & 13 & 4 & 6 & 8 \\
\hline 12 & 39 & Diploma & Housewife & 19 & 1 & 7 & 12 \\
\hline
\end{tabular}

Table 2. Themes and Sub-themes Derived From Data Analysis

\begin{tabular}{ll}
\hline Themes & Sub-themes \\
\hline Endless pregnancy & $\begin{array}{l}\text { Brittle pregnancy } \\
\text { Painful and endless suffering for motherhood }\end{array}$ \\
\hline \multirow{2}{*}{$\begin{array}{l}\text { Thirst of support and } \\
\text { affirmation }\end{array}$} & $\begin{array}{l}\text { Spousal support } \\
\text { Familial and relatives' support } \\
\text { Medical team's support }\end{array}$ \\
\hline $\begin{array}{l}\text { Utilization of religious } \\
\text { beliefs }\end{array}$ & $\begin{array}{l}\text { Acceptance of the divine destiny } \\
\text { Being thankful to God }\end{array}$ \\
\hline
\end{tabular}

in abortion, the doctors could not keep the pregnancy, and I felt great regret in my heart". Likewise, participant No. 8 (25 years old), while weeping and crying, asserted that: " $I$ am like someone who has experienced the pain of labor and the periods of gestation and pregnancy, but I regret hearing the baby's voice and the word of mama".

Thirst for Support and Affirmation

Thirst for support and affirmation contained three subthemes, including spousal support, familial and relatives' support, as well as the medical team's support. The need for support was regarded as one of the important needs which is felt by women with recurrent miscarriages. Participants explained that they needed their spouse's understanding and accompany a secure family environment, and the support of the relatives to get along the post-abortion period. Physical and psychological support from medical staff was also considered important. The respondents had sometimes felt this emotional and supportive gap from the bottom of their hearts.

\section{Spousal Support}

Concerning spousal support, participant No. 4 (36 years old) mentioned that: "When I realized that I was pregnant, I wanted my husband to always be beside me and understand what conditions I am through and support me more than before; however, my husband did not come to me when he realized that I was pregnant and even paid no attention to me when it was aborted". Participant No. 2 (25 years old) also commented that: "I wanted my husband not to leave me alone in those difficult circumstances".

\section{Familial and Relatives' Support}

Regarding familial and relatives' support, participant No. 4 (36 years old) remarked that: "My mother permanently asked about my pregnancy and period every month, and she even checked all my tests if I became pregnant. When she knew that my period was delayed, she became more sensitive about this issue, and I felt better when she did these followups". Further, participant No. 1 (36 years old) explained that: "Thank God, everyone around me treated and talked with me in a normal and good manner, and everything was normal, which further helped me tolerate the recurrent abortive process". Similarly, participant No. 6 (38 years old) expressed that "My uncle and I went to Hajj and this was the best thing I did. I was very relaxed. In addition, we went to Germany the same year and I became very happy and pleased with such support".

\section{Medical Team's Support}

Regarding the support from the medical team, participant No. 5 (a 39-year-old woman) talked about the medical staff and how they treat women with recurrent miscarriages: "It is very good if the medical staff is very knowledgeable and skilled and informs the mother about this (abortion), taking into account her spirit. Some nurses and midwives support us a lot after abortion and this is very considerable." However, participant No. 12 (39 years old) complained that the medical staff did not understand her condition and mentioned that: "You experienced spotting without any reason so that thousands of thoughts came to your mind, but nurses and midwives paid no attention to my feeling at all. All of a sudden, they come to me and say that it is 
aborted regardless of the person's spirit. It's very hard".

Utilization of Religious Beliefs

The acceptance of divine destiny and being thankful to God were the two subcategories of this theme.

\section{Acceptance of Divine Destiny}

Most participants emphasized the importance of religious beliefs regarding adapting to recurrent miscarriages and accepting this phenomenon in their lives. In this respect, participant No. 5 (39 years old) indicated the following views on accepting the divine destiny: "It implies that whatever all these conditions of the things (whether) are from my own side or my husband's side, we (do) believe in the fate which God has decided for us. Even our families supported us in this case, and they mentally supported me very well. Moreover, if this sustenance bread is our God's decided fate, in God we trust, and He is the one who knows what is better and expedient for us". Satisfaction with divine destiny is one of the cases affecting participants' sympathy and adaptability. In this regard, participant No. 7 (29 years old) declared that: "Thank God, everything is good now since human life is better, and they have more faith in God, and He knows better why He deprived us of this blessing. It is certainly great wisdom in this respect. Isn't it?". Participant No. 1 (36 years old) mentioned that: "Belief in God's decided fate and sustained blessing is in the heavens and also in what you are promised. Additionally, we are all satisfied with God's pleasure". Most participants thanked God while facing these conditions. They referred to aborted fetuses as their children and selected a name for each one of them. Concerning the sub-theme of being thankful to God, participant No. 12 (39 years old) expressed that: "God bless our son, this same son will marry and have a baby tomorrow. If we nurture him well and be able to provide him a good life, we will be thankful to God".

\section{Being Thankful to God}

Participant No. 2 (25 years old) indicated that: "Thank to God that I have three children in Paradise that will intercede for us on the Day of Judgment." Smiling, she recited this verse, "Wealth and children are the adornments of the present life...God Almighty has spoken the truth". This sentence was repeated by most of the participants whose belief in it made them feel relaxed. Participant No. 9 (39 years old) also declared that: "Well, I took pills as a contraceptive method and became fat consequently. Whatever God has decided for me, I am just thankful to Him without any objection and may God bless the very things (that) I have. My husband does not want me to have a baby. He says God blesses these (children), and I have no objections to God's destiny". In addition, participant No. 4 (36 years old) expressed that: "One thing I say is that a kid is referred to as adornment in Qur'an, so it is a source of sustenance thus not all the people should necessarily give birth to a child. The important thing is to live properly together, and we must have strong faith in God so that we can overcome all the difficulties and to continue the rest of our lives. We should not object to God's destiny. We are all under God's command".

\section{Discussion}

To the best of our knowledge, this study was the first one to examine the perception and experience of recurrent miscarriage through the lens of the Arab woman in the United Arab Emirates. Although there is little research about women's experience with recurrent abortion, the findings of our study support these previous studies. Based on the results of the current study, endless pregnancy, as the first theme, included brittle pregnancy and painful and endless suffering for motherhood. Recurrent miscarriage gave women a sense of endless pregnancy that was similar to the emerged theme of going back to "square one," in a study about the lived experience of abortion after infertility treatments (15). The emerged themes in the present study showed endless suffering for motherhood. Similarly, the result of a qualitative study on the experiences of infertile women seeking assisted pregnancy revealed that infertile women struggled to achieve pregnancy while they hoped to overcome their problems (16). Consistently, Amato et al. in another qualitative study on the psychological experiences of women with recurrent abortion reported loneliness in suffering and social isolation (17). Likewise, Ockhuijsen et al, in their study on coping with recurrent miscarriage, found two core categories of bracing and uncertainty in the waiting period for the ongoing pregnancy. Women who experienced more abortions were more likely to use bracing for the worst as their coping strategy to deal with uncertainty (18). Conversely, in the present study, women likened their pregnancies as fragile.

In addition, thirst for support and affirmation was the second theme obtained in this study, which encompassed several sub-themes such as spousal support, familial and relatives' support, and medical team's support. Social support plays an important role in achieving adaptability in these women. Further, familial relationships are a source of power and spousal support is very essential in such a situation. Similarly, the findings of a study by Shurack indicated that women benefit from support during and after abortions, especially from their spouse, family, friends, and health care providers. The participants reported that they experienced silence and embarrassment because of recurrent miscarriage, and thus talking openly about this condition is a significant aspect of coping with the problem (19). Furthermore, Meaney et al found obtaining support and coping with abortion as one of the themes of their study and indicated that individuals should attempt to fill their time in order to cope with abortion and that those who need special support should refer to their family and counselor. Moreover, establishing intimate contact with family and friends is considered important because they are the best support in this situation and can help overcome this stage (20). Consistent with the present 
study, Cacciatore reported that social support is the main source of support that is provided by various sources (i.e., parents, support groups, counselors, and health care providers), and therefore, mothers who received no support expressed more disappointment (21). In another study, Sutan et al also showed that friends' support played an important role in adapting to perinatal death (22).

Conversely, Meaney et al found that participants were unwilling to receive formal counseling services and needed more help from their families, friends, and other support groups. The above-mentioned researchers also talked to participants about medical staff and health care providers and came across a theme called "the hospital environment, the management of miscarriage": this means that if hospitals have proper management and pay attention to patients who have or need to undergo abortion, they can reduce such patients' stress and worry and thus prevent the onset of depression and sadness (20). The lack of attention to the post-abortion feelings of the individuals can lead them to sadness. Therefore, if couples are supported and their perception towards recurrent miscarriage is understood, they can be assisted to cope with the feeling of sadness (23).

Most of the obtained themes in various studies are similar to the categories obtained in the present study. The thirst for support among Arab woman is similar to women in different other countries, which shows the importance of this issue. When these women experience abortion, they need to communicate with a clinical worker at a hospital in-person or on the telephone (24). The lack of attention of care providers to the emotional aspects of women with early abortion can also affect their treatment management. Most women are admitted to the hospital and the uterus's contents are removed by curettage. The patient then goes back home and refers to the hospital only in the case of further problems. This short hospitalization and the removal of uterus's contents are regarded as important factors in the development of depression and psychological problems (23). On the other hand, compassionate and empathic behavior is the prerequisite for recovery. Being aware of the suffering that couples experience following a spontaneous abortion can lead to the release of emotions and feelings and enable the couples to take it as part of their lives instead of spending their time thinking about the experience of the loss of life (4). Having a successful pregnancy in most women is a lovely feeling while having abortive pregnancy can cause many problems for women. Collins referred to bad experiences such as the ridicule and oppression of women who had an unsuccessful pregnancy (25). Adebayo, on the other hand, analogized women as a mask that is freed by breaking the fence of paternal culture and reveals a female identity (26). In women with unknown recurrent miscarriage, it is possible to achieve great prognosis and pregnancy outcomes without drug interference by simply providing supportive care (27). Women are more in need of deep awareness and perception and empathic care from health specialists. Family support can also be taken into account for reducing the women's sense of frustration, insecurity, and loneliness (2).

The third important theme of the present study was the utilization of religious beliefs, which contained the acceptance of divine destiny and being thankful to God. Each of these themes and sub-themes was an experience and perception that was expressed through the viewpoint of an Arab woman. In a study on Saudi women, Saad et al concluded that fertility health was a very sensitive issue that was important in terms of environmental, physical, biological, behavioral, cultural, economic, and social aspects (28). Pregnancy and birth are believed to have a cultural pattern, and women's knowledge, beliefs, and behaviors are formed based on their cultural contexts (29). Additionally, culture plays an important role in women's experiences and the perception of fertility issues. Some previous studies revealed that religious and cultural beliefs help women to deal with the sadness caused after infertility or perinatal death $(30,31)$. Likewise, Kilshaw et al referred to demonic possession as one of the sub-themes, that is, women think that human beings are captured by jinns who enter the human body and cause infertility and abortion in women. Therefore, they recommend praying and perseverant remembrance of Allah in the case of possessed women. On the other hand, they referred to a supernatural force as the cause of abortion and this force was the creator of this world. In other words, the women of this study attributed the cause of their abortion to God's will. For this reason, religious beliefs can protect women against evil eyes during pregnancy and prevent abortion (32). A woman with the experience of abortion is often considered sinister and thus forbidden to approach young women lest she transfers her evil influence onto the other pregnant women (33). Hence, cultural and social expectations and grief for the loss of the fetus create challenges for women. The results of a qualitative study also showed that it was very important to be aware of the health and cultural needs of women exposed to the same reproductive risks in different cultures (34). Although health care providers are not expected to be aware of all the cultural customs of their clients, they are still expected to interact with all clients based on the clients' respect for their knowledge.

\section{Conclusions}

In general, this study was conducted in the United Arab Emirates women who experienced recurrent miscarriages which implies endless pregnancy in the eyes of Arab women. In addition, it awakens a thirst for support and affirmation and leads to the utilization of religious beliefs. These parameters greatly reduce their problems and discomfort. It is worth mentioning that clinical teams should be aware of the internal and external pressures regarding acting on women in their cultural contexts 
and protect patients from the potential dangers of recurrent miscarriages. Therefore, identifying the risks and consequences of recurrent miscarriages among Arab women, as well as adopting preventive measures and improving the quality of care in this vulnerable stratum requires special attention.

\section{Conflict of Interests}

Authors declare that they have no conflict of interests.

\section{Ethical Issues}

The present research was approved by the Ethics Committee of Tehran University of Medical Sciences (IR.TUMS.FNM.REC.1396.3227) and permission was obtained from the authorities of the Medical School of the UAE University of Medical Sciences.

\section{Financial Support}

This study was financially supported by the Research Affairs of Tehran University of Medical Sciences (grant No. IR.TUMS.FNM.REC.1396.3227).

\section{Acknowledgments}

This article is derived from a doctoral thesis on reproductive health submitted in Tehran University of Medical Sciences. The authors would like to thank all who participated in this research.

\section{References}

1. Nazare B, Fonseca A, Canavarro MC. Grief following termination of pregnancy for fetal abnormality: does marital intimacy foster short-term couple congruence? J Reprod Infant Psychol. 2012;30(2):168-179. doi:10.1080/0 2646838.2012.693154

2. Chaloumsuk N. Women's experiences of miscarriage and termination of pregnancy for fetal anomaly in Thailand: a phenomenological study. University of East Anglia; 2013.

3. Branch DW, Gibson M, Silver RM. Recurrent Miscarriage. New Eng J Med. 2010;363(18):1740-1747. doi:10.1056/ NEJMcp 1005330

4. Wolman I. Berek and Novak's Gynecology 15th Edition: Lippincott Williams and Wilkins, 2012, 1560 pp, Hardcover, Rs. 2659 on www.flipkart.com, ISBN-139788184736106, ISBN-10818473610X. J Obstet Gynaecol India. 2014;64(2):150-151. doi:10.1007/s13224-014-0538-Z

5. Rizvi A. Emirati woman who suffered 10 miscarriages gives birth to baby girl. The National website. 2015; https://www. thenational.ae/uae/health/emirati-woman-who-suffered10-miscarriages-gives-birth-to-baby-girl-1.25513.

6. CIA World Factbook. CIA website. https://www.cia.gov/ Library/publications/the-world-factbook/geos/ae.html. Published 2014.

7. World Health Organization (WHO). United Arab Emirates. http://www.who.int/countries/are/en/. Published 2015.

8. Mander S, Miller YD. Perceived safety, quality and cultural competency of maternity care for culturally and linguistically diverse women in Queensland. J Racial Ethn Health Disparities. 2016;3(1):83-98. doi:10.1007/s40615-

\section{5-0118-7}

9. Sejourne N, Callahan S, Chabrol H. Support following miscarriage: what women want. J Reprod Infant Psychol. 2010;28(4):403-411. doi:10.1080/02646830903487375

10. Adolfsson A, Larsson PG, Wijma B, Bertero C. Guilt and emptiness: women's experiences of miscarriage. Health Care Women Int. 2004;25(6):543-560. doi:10.1080/07399330490444821

11. Rai R, Regan L. Recurrent miscarriage. Lancet. 2006;368(9535):601-611. doi:10.1016/s0140-6736(06)692040

12. Evaluation and treatment of recurrent pregnancy loss: a committee opinion. Fertil Steril. 2012;98(5):1103-1111. doi:10.1016/j.fertnstert.2012.06.048

13. Graneheim UH, Lundman B. Qualitative content analysis in nursing research: concepts, procedures and measures to achieve trustworthiness. Nurse Educ Today. 2004;24(2):105112. doi:10.1016/j.nedt.2003.10.001

14. Guba EG. Criteria for assessing the trustworthiness of naturalistic inquiries. ECTJ. 1981;29(2):75. doi:10.1007/ bf02766777

15. Freda MC, Devine KS, Semelsberger C. The lived experience of miscarriage after infertility. MCN Am J Matern Child Nurs. 2003;28(1):16-23. doi:10.1097/00005721-20030100000005

16. Ranjbar F, Behboodi-Moghadam Z, Borimnejad L, Ghaffari SR, Akhondi MM. Experiences of infertile women seeking assisted pregnancy in Iran: a qualitative study. J Reprod Infertil. 2015;16(4):221-228.

17. Amato HC. A qualitative investigation of the psychological experiences of recurrent miscarriage among women. Fordham University; 2008.

18. Ockhuijsen HD, Boivin J, van den Hoogen A, Macklon NS. Coping after recurrent miscarriage: uncertainty and bracing for the worst. J Fam Plann Reprod Health Care. 2013;39(4):250-256. doi:10.1136/jfprhc-2012-100346

19. Shurack ELZ. Pregnancy loss: women's experiences coping with miscarriage. University of British Columbia; 2015.

20. Meaney S, Corcoran P, Spillane N, O'Donoghue $\mathrm{K}$. Experience of miscarriage: an interpretative phenomenological analysis. BMJ Open. 2017;7(3):e011382. doi:10.1136/bmjopen-2016-011382

21. Cacciatore J. The unique experiences of women and their families after the death of a baby. Soc Work Health Care. 2010;49(2):134-148. doi:10.1080/00981380903158078

22. Sutan R, Amin RM, Ariffin KB, Teng TZ, Kamal MF, Rusli RZ. Psychosocial impact of mothers with perinatal loss and its contributing factors: an insight. J Zhejiang Univ Sci B. 2010;11(3):209-217. doi:10.1631/jzus.B0900245

23. Lavender T. Exploring Bereaved Fathers' Experiences of Pregnancy Loss: A Phenomenological Study. City University of Seattle; 2016.

24. Meaney S, Corcoran P, O’Donoghue K. OP61 Women's experience of miscarriage; a qualitative study. J Epidemiol Community Health. 2015;69(Suppl 1):A35-A36. doi:10.1136/jech-2015-206256.60

25. Collins PH. Toward an Afrocentric feminist epistemology. Turning Points in Qualitative Research. London: Routledge; 1990.

26. Adebayo A. Feminism and black women's creative writing: 
Theory, practice, and criticism. Ibadan: AMD Publishers; 1996:53.

27. Royal College of Obstetricians and Gynaecologists (RCOG). The investigation and treatment of couples with recurrent first-trimester and second-trimester miscarriage. RCOG; 2011.

28. Saad AA, El-Sikaily AMA, El-Badawi E-S, et al. Relation between some environmental pollutants and recurrent spontaneous abortion. Arab J Chem. 2016;9 Suppl 1:S787-S794. doi:10.1016/j.arabjc.2011.08.011

29. Cosminsky S, Childbirth and Change: A Guatemalan Study. In: MacCormack CP, ed. Ethnography of fertility and birth. New York, Academic Press, 1982. 205-29.

30. Cowchock FS, Lasker JN, Toedter LJ, Skumanich SA, Koenig HG. Religious beliefs affect grieving after pregnancy loss. J Relig Health. 2010;49(4):485-497. doi:10.1007/s10943-009-
9277-3

31. Ranjbar F, Akhondi MM, Borimnejad L, Ghaffari SR, Behboodi-Moghadam Z. Paradox of Modern Pregnancy: A Phenomenological Study of Women's Lived Experiences from Assisted Pregnancy. J Pregnancy. 2015;2015:543210. doi:10.1155/2015/543210

32. Kilshaw S, Omar N, Major S, et al. Causal explanations of miscarriage amongst Qataris. BMC Pregnancy Childbirth. 2017;17(1):250. doi:10.1186/s12884-017-1422-5

33. Sultana A. Miscarriages and induced abortions! The plight of rural women (A case study of Punjabi Village). Journal of the Research Society of Pakistan. 2008;45:1-10.

34. Batool SS, Azam H. Miscarriage: Emotional burden and social suffering for women in Pakistan. Death Stud. 2016;40(10):638-647. doi:10.1080/07481187.2016.1203376

(c) 2019 The Author (s); This is an open-access article distributed under the terms of the Creative Commons Attribution License (http://creativecommons.org/licenses/by/4.0), which permits unrestricted use, distribution, and reproduction in any medium, provided the original work is properly cited. 